\section{Halley mission on course}

THE era of exploration of Halley's comet is at last beginning to unfold. In two days' time, the first of a clutch of satellites due to pass by Halley sometime in March 1986 should be launched. VEGA, or "VenusHalley", a Soviet-French collaboration which will drop probes into the atmosphere of Venus on the way to Halley, should get away this Saturday.

One French participant described VEGA recently as "a fantastic mission, really gorgeous". Soviet space technology is sometimes rough-and-ready in comparison with that of the United States, but VEGA has some beautiful equipment, according to Jean-Loup Berthod of the Verrières-le-Buisson space laboratory of the Centre National de la Recherche Scientifique.

For instance, VEGA will carry the first planetary mission camera equipped with an advanced charge-coupled-device (CCD) imaging surface, says Berthod. CCDs are "much more flexible"' and linear than the standard "videcon" detection system, and "the future for space exploration is CCD" says Berthod. The US Galileo trip to the outer planets will use CCD imaging. But VEGA will be first, using a camera built by the Soviet Union, Hungary and France and with a Soviet CCD. French laboratories have made calibrations of the device and "at the present time it seems to be good".

There will be two VEGAs with identical payloads, the second to be launched a few days after the first, and each should arrive at Venus in June next year. Each VEGA will then divide into two parts, one to fly on to Halley and the other to descend onto Venus ("the Soviet's pet planet", as Berthod describes it).

Each VEGA descent probe should eject a small balloon carrying instruments to measure local pressure and temperature, and a small radio transmitter which will be followed on Earth for some days by very long baseline radio interferometry (VLBI) with the US Deep Space Network and the French and Soviet networks. This will enable the first measurement of wind speeds and directions in the venusian upper atmosphere.

The French interest has been mostly to measure a sulphur dioxide profile through the atmosphere, to learn if it may be concerned with volcanic activity. Pioneer V indicated a tenfold decrease in upper atmosphere concentrations of the gas, suggesting that the high levels detected earlier may have been transitory.

As for Halley, the first VEGA probe should reach the comet on 8 March 1986, five days before the European mission Giotto. VEGA-1 is due to pass at 10,000 $\mathrm{km}$ from the cometary nucleus, following the nucleus with the CCD camera on a tracking platform. VEGA information will be relayed to the European Space Agency to help it to make the last targeting adjustment to Giotto, which is due to go much closer - within $500 \mathrm{~km}$ on the sunlit side and into the dust cloud. VEGA-2 will pass at $5,000 \mathrm{~km}$, but it has not been decided yet whether it will go before or after Giotto (which is quite likely to be destroyed in the encounter).
"The Soviets wanted survival, and so had to go outside the large dust cloud", says Berthod. And they also wanted good pictures of the nucleus. Hence the CCD camera, and hence also the distance of approach. At a fly-by velocity of some 70 $\mathrm{km}$ per second, the rate at which the camera could be turned to keep track of the nucleus fixed a fly-by distance of a few thousand kilometres. Giotto will also attempt to track the nucleus, but by turning a lighter mirror system.

\title{
Comparison of biotechnology stock indexes
}

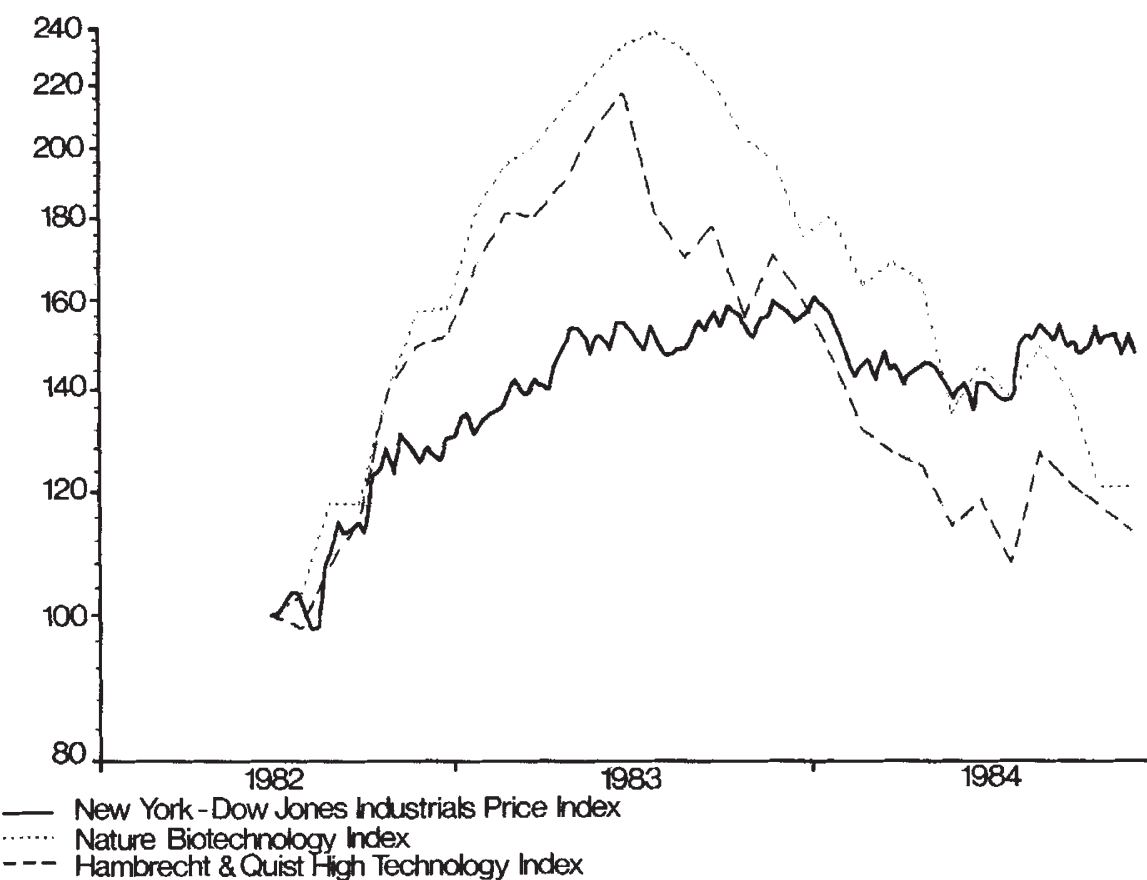

A comparison of the Nature index of biotechnology stocks (which started at 100 on

Hambrecht \& Quist indexes to November 1984. (Source: Datastream/Peter Laing of 25 June 1982) with the Dow Jones and Biotechnology Investments Limited.)

\section{Nature index of biotechnology stocks}

\begin{tabular}{|c|c|c|c|c|c|}
\hline $\begin{array}{l}\text { 12-Month } \\
\text { high }\end{array}$ & $\begin{array}{l}\text { 12-Month } \\
\text { low }\end{array}$ & Company & $\begin{array}{l}\text { Close } \\
\text { previous } \\
\text { month }\end{array}$ & $\begin{array}{l}\text { Close } \\
\mathbf{3 0} \text { November }\end{array}$ & Change \\
\hline 14 & $53 / 4$ & Biogen (Switzerland) & 7 & $53 / 4$ & $-11 / 4$ \\
\hline 2 & 1 & Bio-Logicals (Canada) & $15 / 16$ & $13 / 8$ & $+1 / 16$ \\
\hline $14^{3} / 8$ & $41 / 2$ & Bio-Response (USA) & 6 & $41 / 2$ & $-11 / 2$ \\
\hline $14 \% / 8$ & $83 / 4$ & Cetus (USA) & $10 \%$ & $87 / 8$ & $-13 / 8$ \\
\hline $10 \%$ & $4 ! / 4$ & Collaborative Research (USA) & $41 / 2$ & $51 / 4$ & $+3 / 4$ \\
\hline $19 \%$ & $11 \frac{1}{2}$ & Damon (USA) & $12 \%$ & $113 / 4$ & $-3 / 8$ \\
\hline $261 / 4$ & $113 / 4$ & Enzo-Biochem (USA) & $18 ! / 4$ & $15 \%$ & $-31 / 8$ \\
\hline $10 \%$ & $3 \%$ & Flow General (USA) & $4 \%$ & $3 \%$ & $-11 / 4$ \\
\hline $42 ! / 4$ & $283 / 4$ & Genentech (USA) & $287 / 8$ & $331 / 4$ & $+43 / \mathrm{s}$ \\
\hline $10^{3 / 4}$ & $41 / 2$ & Genetic Systems (USA) & $61 / 2$ & 6 & $-1 / 2$ \\
\hline $17 ! / 4$ & $6 \% / 8$ & Genex (USA) & $71 / 8$ & $65 / 8$ & $-1 / 2$ \\
\hline 23 & 11 & Hybritech (USA) & $153 / 4$ & $151 / 4$ & $-1 / 2$ \\
\hline $16 ! / 4$ & $61 / 4$ & Molecular Genetics (USA) & 7 & $6 ! / 4$ & $-3 / 4$ \\
\hline $151 / 2$ & $81 / 4$ & Monoclonal Antibodies (USA) & $10^{1 / 2}$ & 9 & $-1 \frac{1 / 2}{2}$ \\
\hline $607 / 8$ & $20 \%$ & Novo Industri A/S (Denmark) & $207 / 8$ & $241 / 2$ & $+3 \%$ \\
\hline $223 / 4$ & $14 ! / 2$ & Pharmacia (Sweden) & $16 ! / 4$ & $16^{1 / 8}$ & $-1 / 8$ \\
\hline
\end{tabular}

Closing prices are for the last Friday of the month. For over-the-counter stocks, bid price is quoted; for stocks on the American and New York exchanges, the transaction price. Nature's weighted index of biotechnology stocks stood at $\mathbf{1 2 1}$ on 30 November, the same as a month earlier. Data from E.F. Hutton, Inc. 